\title{
Projeto: Ylê ayié yaya ilera (Saúde plena na casa desta existência): equidade e integralidade em saúde para a comunidade religiosa afro-brasileira
}

Márcia Constância Pinto Aderne Gomes ${ }^{1}$

\section{Introdução}

A Política Nacional de Saúde Integral da População Negra (Brasil, 2001a) definiu o conjunto de princípios, marcas, diretrizes e objetivos voltados para a melhoria das condições de saúde desse segmento da população. Incluiu ações de cuidado e atenção à saúde, bem como de gestão participativa, controle social, produção de conhecimento, formação e educação permanente de trabalhadores de saúde, visando à promoção da equidade em saúde da população negra. Este trabalho pretende relatar uma experiência de implantar um serviço de saúde dentro de um espaço cedido em um terreiro de candomblé na zona norte do município do Rio de Janeiro.

A partir da reflexão de indicadores de saúde, revisão documental da política para saúde da população negra e contatos com lideranças do Movimento Negro e de religiões de matrizes africanas, surgiu a necessidade, ou melhor, a possibilidade de construção de um projeto de atenção integral e equânime para um grupo de mulheres negras, pobres e vinculadas ao Candomblé.

\section{Desigualdades raciais e indicadores de saúde}

A classificação em termos de raça, usada no Brasil com fins de estudos demográficos, é, desde 1991, a do IBGE, a qual entende que o indivíduo deve autodeclarar sua cor, sem levar em consideração a categoria biológica que a escolha acarretaria. Enfim, é uma classificação arbitrária, mas que permite ao indivíduo definir em que raça ele se considera inserido (Oliveira, 2004).

$\mathrm{O}$ censo brasileiro pede às pessoas que se classifiquem dentro de uma das cinco categorias seguintes: branco, preto, pardo, indígena ou amarelo (oriental). Pretos e pardos constituem $45 \%$ de toda a população e $98,7 \%$ da população não-branca brasileira (Brasil, 1996). No Brasil, entretanto, assumir-se na categoria racial "negra" traz consigo diversos elementos conflituosos, já que a sociedade ainda vê como "certos", "bons" e "bem-sucedidos", pouquíssimos elementos dessa categoria (Oliveira, 2004).

O Relatório do Desenvolvimento Humano do PNUD, intitulado "Racismo, pobreza e violência" (Brasil, 2005), analisou as desigualdades raciais em áreas
Centro Municipal de Saúde Milton Fontes Magarão (SMSDC/RJ) Av. Amaro Cavalcanti, 1387. Engenho de Dentro Rio de Janeiro, RJ, Brasil. 20.735-041 marconstanci@hotmail.com 
como renda, educação, saúde, emprego, habitação e violência, e concluiu que os negros estavam em situação pior em todos os indicadores. O relatório mostrou que as diferenças entre brancos e negros apontaram, em alguns casos, uma defasagem de mais de uma geração. A porcentagem de homens negros com curso superior completo, em 2000, era menor que a dos homens brancos em 1960. A renda per capita dos brancos de 1980 era o dobro da dos negros em 2000. Do mesmo modo, a taxa de analfabetismo dos negros, em 2000, era maior que a dos brancos em 1980. Os negros apresentavam, em 2000, esperança de vida semelhante à dos brancos em 1991. O estudo apontou também que a taxa de homicídio entre os negros é o dobro da dos brancos. Este relatório contribuiu para o debate a respeito do racismo no Brasil, pois revelou indicadores incontestáveis de manifestação desse fenômeno. Racismo, pobreza e violência, afirmou o relatório, são "problemas que se imbricam de tal forma que só podem ser confrontados conjuntamente, combinando tanto ações de cidadania e de participação com políticas públicas, sejam elas de caráter universalista ou focalizada" (Brasil, 2005, p.12).

O município do Rio de Janeiro, cuja maioria da população é branca, era, em 2000, a segunda cidade negra do Brasil, com 2,36 milhões de habitantes fazendo parte deste grupo racial ou de cor (Paixão, 2003). A cidade do Rio de Janeiro abrigava, na ocasião, 831,8 mil negros pobres. Este número equivalia a $33,3 \%$ dos negros abaixo da linha da pobreza no estado do Rio de Janeiro. O percentual de negros abaixo da linha da indigência era de $9 \%$ frente a 3,9\% dos brancos (Paixão, 2003).

Outra pesquisa constatou que as gestantes negras (pardas e pretas) têm maior dificuldade no acesso aos cuidados e informações de saúde (Leal, Gama, Cunha, 2005). Em relação à consulta de pré-natal, os dados do Ministério da Saúde informam que a mulher negra (preta e parda) tem menos acesso à consulta de pré-natal, podendo estar mais exposta ao risco de morte materna e fetal.

Travassos e Martins (2004) realizaram uma revisão de conceitos de "acesso" e de "utilização dos serviços de saúde". As autoras identificaram pontos de distinção e de articulação entre estes conceitos e concluíram que, apesar das discordâncias nas terminologias empregadas e na abrangência destes, a ideia que prevalece é que acesso é uma dimensão do sistema de saúde associada à oferta, e que há uma tendência de deslocar o conceito de acesso para os resultados dos cuidados de saúde. Assim, para melhorar as condições de saúde das pessoas, seria necessário formular políticas para um melhor desempenho dos sistemas de saúde, a partir da construção de modelos que incorporem as particularidades de cada contexto a ser enfrentado.

\section{Aproximação com o tema}

Em dezembro de 2006, fomos procurados, na Coordenação de Saúde da Área $3.2{ }^{2}$ por uma líder religiosa afro-brasileira que solicitava a implantação de um Posto de Vacinação (PV) em seu Barracão (sede do Terreiro de Candomblé) para atender aos moradores da região. Na ocasião também foram discutidas questões a respeito do acesso e da qualidade da atenção à saúde prestada a um grupo particular de mulheres negras, pobres e vinculadas à religião de matriz afrobrasileira, que frequentavam seu terreiro - "Ilê ya manjele o" - em Água Santa (subúrbio do município do Rio de Janeiro).

Essa líder religiosa e social representava 75 mulheres e suas famílias, todas vinculadas ao seu Terreiro de Candomblé, por questões religiosas e também
${ }^{2}$ O Município do Rio de Janeiro é dividido em dez áreas de planejamento de ações de saúde. A Área Programática 3.2 abrange 26 bairros (Jacarezinho, Inhaúma Tomas Coelho, Jacaré, Del Castilho, Pilares, Engenho da Rainha, Piedade, Engenho de Dentro, Engenho Novo, São Francisco Xavier, Água Santa, Encantado, Lins de Vasconcelos, Maria da Graça, Abolição, Higienópolis, Cachambi, Riachuelo, Rocha e Méier), totalizando uma população de 561.474 habitantes (Instituto Pereira Passos, 2002), distribuídos em $44 \mathrm{Km}^{2}$, sendo $70 \%$ usuários do SUS. 
${ }^{3}$ Machado e Carvalho (2004), escrevendo sobre a dor da invisibilidade do negro, trazem diversos autores que associam a invisibilidade do negro brasileiro como consequência concreta, eficiente e direta do racismo. Oportunamente, retornaremos ao assunto. pelo trabalho de cunho social e de educação em saúde (prevenção de doenças sexualmente transmissíveis - DST e de aids) desenvolvido por ela e algumas de suas "filhas-de-santo".

Nosso objetivo inicial era escutar e qualificar as necessidades de atenção à saúde do grupo de mulheres trazidas por essa líder, conhecer seu território, apresentar as unidades e os serviços oferecidos pela rede assistencial da CAP 3.2, e iniciar um estudo de viabilidade para a realização do PV no espaço do terreiro.

No cumprimento de nossos objetivos, escutamos as queixas apresentadas, que foram anotadas para posterior discussão com os profissionais e gestores de saúde da CAP 3.2. As queixas incluíam: dificuldade de acesso, assistência não-resolutiva, preconceito racial, preconceitos com a pobreza, maus-tratos, preconceitos relacionados à prática de religião afro-brasileira e "invisibilidade". Este último nos causou um grande estranhamento, pois como seria possível que um ser humano fosse invisível? Só entendemos o que isto significava quando conhecemos as mulheres, as examinamos e ouvimos suas histórias, soubemos como evoluíram seus sinais e sintomas, observamos suas várias receitas e/ou saquinhos cheios de medicamentos. As "invisíveis" ${ }^{3}$ tinham acesso aos serviços, eram atendidas, acompanhadas, medicadas e faziam exames, porém, ao vê-las e escutá-las, tivemos a impressão de que nunca elas tinham sido vistas.

$\mathrm{Na}$ ocasião, conhecemos o terreiro e a mãe-de-santo nos apresentou o espaço onde as práticas religiosas aconteciam e as outras atividades de cunho social (oficinas de geração de renda por meio de grupos de artesanato, reforço escolar para as crianças, e capacitação e palestras sobre DST/Aids, violência, planejamento familiar e outros temas de promoção à saúde). Na ocasião, a líder religiosa manifestou seu desejo de transferir as atividades não-religiosas e montar um consultório médico na casa em frente para atender às mulheres frequentadoras do terreiro.

Comprometemos-nos a estudar esta possibilidade, pois a população que frequentava este espaço religioso habitava a área de responsabilidade sanitária da CAP 3.2 e comunidades de alta vulnerabilidade social. Deveríamos, então, construir um projeto que pudesse confrontar as demandas de saúde da população da área a partir do diagnóstico de saúde deste grupo, para planejar ações de promoção de saúde, prevenção de doenças e assistência a estas mulheres, suas famílias e comunidade pautadas nos princípios do SUS, nos moldes da Estratégia de Saúde da Família (Brasil, 2001b, 2000, 1997). Acreditamos que as transformações que podem ser alcançadas na reorganização da atenção básica decorrem da adoção de ações institucionais globalizantes e includentes de inovações das práticas de saúde presentes nas diretrizes operacionais do PSF (Gomes, 2005).

Para cada objetivo, foram pensados ações e prazos. As reuniões formais e informais para planejar e executar o projeto foram as que mais demandaram nossos esforços e tempo.

\section{Objetivos gerais}

- Planejar e organizar o acesso de mulheres negras, pobres e vinculadas à religião de matriz afro-brasileira em situação de exclusão social.

- Viabilizar o atendimento das necessidades de saúde desta população a partir do conhecimento das estratégias que são empregadas, com o objetivo de oferecer alternativas contextualizadas.

- Promover ações que se destinem à promoção de saúde, à prevenção e controle de doenças infectocontagiosas e/ou crônicas e à inclusão de forma resolutiva na rede de serviços de saúde existente. 
Os objetivos específicos

- Realizar revisão bibliográfica sobre a saúde da população negra, indicadores de saúde, religiões de matriz afro-brasileira, exclusão, preconceito e intolerância.

- Construir uma agenda de atenção às mulheres negras e suas famílias.

- Planejar e organizar o acesso aos serviços de saúde e identificar as necessidades de acesso a serviços de atenção básica e/ou especializada.

- Iniciar um projeto-piloto:

- Montagem de consultório simplificado e transitório4;

- Providenciar, junto aos diretores de unidades próximas, o empréstimo ou doação de bens para montagem do consultório simplificado transitório;

- Criar cotas de medicamentos, insumos e outros produtos de consumo;

- Recrutar profissionais para montar equipe multidisciplinar;

- Registrar ações, consultas, encaminhamentos, procedimentos, acompanhamento, pedidos de material, cotas, gastos, e outros dados relativos ao projeto.

- Divulgar e discutir esta experiência em diversos fóruns.

- Avaliar o projeto.

- Contatar outras lideranças religiosas para aumentar a parceria saúde e religião de matriz afro-brasileira.

- Iniciar mapeamento do território de moradia dessas mulheres.

- Realizar oficinas de integração entre profissionais de saúde e lideranças religiosas.
${ }^{4}$ Nossa intenção não é retirar esta população da rede assistencial a partir da criação de novos espaços de atendimento, mas sim construir possibilidades de inclusão dessas pessoas na rede.

\section{Passos metodológicos}

Utilizamos diversos métodos de coleta de dados, tanto quantitativos quanto qualitativos. Foram examinados os documentos referentes à Política de Saúde da População Negra e as estratégias para a cidade do Rio de Janeiro. Paralelamente, foi feita uma revisão da literatura pertinente ao tema, para refletir e fundamentar pontos teóricos que sustentaram a parte analítica deste estudo.

Optamos por uma pesquisa-ação que fosse, acima de tudo, ética - e todos os cuidados estão sendo tomados neste sentido, pois assumimos o compromisso de pensar nela como uma prática social, garantindo a visibilidade dos procedimentos de coleta e análise, construindo uma relação dialógica entre entrevistador e entrevistado (Spink, Menegon, 2000).

Esta dinâmica de investigação e de trabalho, que combina e cruza múltiplos pontos de vista, é conceituada/denominada de triangulação de métodos, e tem, como premissa, a integração subjetiva e objetiva no processo avaliativo, pois, com várias visões de muitos informantes, integrará a análise das estruturas, processos e dos resultados, permitindo a compreensão das relações envolvidas no projeto (Minayo, Assis, Souza, 2005).

\section{Desenvolvimento da proposta}

O projeto foi aprovado para execução pelo Comitê de Ética em Pesquisa e pela coordenadora da área, que nos autorizou a negociar, junto às unidades de saúde, as doações, as cotas de medicamentos e insumos para o projeto. Simultaneamente, a líder religiosa se encarregou de disponibilizar o local. A casa que abriga o projeto sofreu uma pequena reforma, com algumas adaptações, e assim que foi disponibilizada iniciamos o trabalho em junho de 2006.

Nas reuniões formais, nos diversos encontros informais que realizamos, nas visitas às unidades e pelos relatos do cotidiano das práticas de saúde, podemos 
apontar algumas fragilidades, que nos permitiram intuir que a equidade nos serviços de saúde era apenas pro forma. Foram relatados fatos que apontam para a existência de obstáculos para os diferentes tipos de usuários. Nesses encontros, escutamos discursos contundentes que incorporavam argumentos contraditórios e frequentemente desfavoráveis à inclusão dessas mulheres negras, pobres e de religiões de matrizes afro-brasileiras. Estes discursos, provenientes de discussões econômicas, políticas, partidárias, religiosas e outras, serviam para negar-Ihes o acompanhamento, rejeitá-las e às suas famílias, e "fechar a porta de entrada" de suas demandas de saúde. Muitos dos argumentos apresentados convergem para uma visão destes profissionais bem próxima à encontrada por Reis (2000).

Essa pesquisadora analisou as percepções da elite (políticos, burocratas, líderes empresariais, líderes sindicais, elites militares, religiosas, intelectuais e outras, e atores ocupando papéis de destaque em seu meio) sobre a pobreza e as desigualdades sociais no Brasil e em outros países. Ela se debruçou sobre atitudes e valores políticos básicos a respeito de justiça e igualdade social. As conclusões de sua pesquisa apontam que a pobreza e a desigualdade social têm grande importância (absoluta e relativa) para a elite, sendo identificados como principais problemas: a inflação, os problemas da saúde, da educação, pobreza e desigualdade social, considerados como ameaças à democracia.

O que mais chamou nossa atenção foi o reconhecimento da questão da desigualdade, e o não-reconhecimento da interdependência existente entre a missão dos profissionais vinculados a um sistema público de saúde que possui, entre os seus princípios, o da equidade de acesso. Esses profissionais ainda não estariam convencidos "das necessidades de coletivização das soluções sociais e a pertinência de cooperar nestas tarefas" (Reis, 2000, p.499-500).

O Brasil recebeu, ao longo de mais de três séculos, cerca de quatro milhões de africanos como escravos. Embora tenham sido verificadas oscilações no número de escravos importados no decorrer de todo o período escravocrata (Tramonte, 2001), apesar de a sociedade escravagista ter dividido as famílias e espalhado grupos étnicos através do país, os escravos conseguiram manter alguns laços com sua herança étnica. Os colonizadores dividiram os grupos de escravos em diferentes nações (termo referido ao local geográfico de descendência de um determinado grupo étnico e sua tradição cultural); consequentemente, e de forma inesperada, este conceito de nação fomentou a manutenção de várias identidades étnicas, reforçando a importância da transmissão cultural e religiosa (Jensenn, 2001). O sentido da ancestralidade é mantido a partir da linhagem do santo, que não coincide com a linhagem biológica. Estes grupos de múltiplas inter-relações estabelecidas são liderados, em sua grande maioria, pelas ialorixás, ou mães-de-santo. Na família-de-santo, isto é, no sistema da família religiosa de matriz afro-brasileira, a mãe-de-santo é a chefe e todos os seus filhos são iniciados por ela. Assim, a famíliade-santo assume importante papel, pois foi (na época dos escravos) e é capaz de penetrar no vazio emocional, espiritual e social deixado pela família biológica (Tramonte, 2001).

As religiões afro-brasileiras, trazidas por africanos ou originadas de tradições culturais de povos que entraram no Brasil como escravos, nem sempre foram professadas livremente. As diferentes organizações e expressões foram impedidas no período colonial pela Inquisição, quando foram encaradas como feitiçaria e prática diabólica. No Império, foram encaradas como divertimento de negro, sujeitas à autorização da autoridade e a serem perseguidas como feitiçaria e curandeirismo, objeto de penalidade em Códigos de Postura municipais estabelecidos no reinado de D. Pedro II. Depois da proclamação da República, apesar da "liberdade de crença", os terreiros continuaram a ser considerados como casas de diversão, acusados da realização de práticas mágicas e curandeirismo, enquadrados como crime no Código Penal brasileiro de 1890 e crimes contra a saúde pública, sendo encarados como centros geradores de loucura. Em decorrência disso, a religião afro-brasileira sempre enfrentou controle e perseguição da polícia e de órgãos governamentais (Ferreti, 2001). Atualmente, ainda continua sendo encarada de forma preconceituosa, o que impede que os terreiros recebam do poder público o mesmo tratamento que é dispensado a outras religiões, e tem levado muito dos seus adeptos a negarem sua crença e sua vinculação a terreiros (Ferreti, 2001).

Brito e Malandrino (2007) demonstraram que os estudos historiográficos sobre a escravidão fazem poucas referências à religiosidade, ou então, referências genéricas, que não ajudam a compreender a experiência da religiosidade para a vida dos escravos, abordando o tema a partir da instituição religiosa (católica). A negativa de inclusão dessas mulheres aos serviços também foi atribuída ao preconceito 
contra a religião afro-brasileira. Esse preconceito, que no passado encorajou práticas discriminatórias de católicos e de espíritas, hoje se mantém por evangélicos, sobretudo da Igreja Universal do Reino de Deus - IURD (Ferretti, 2001).

Estudos recentes nos permitem afirmar que existem evidências de que a religiosidade está associada ao bem-estar das pessoas e de sua qualidade de vida. A Organização Mundial de Saúde vem desenvolvendo um instrumento denominado "religiosidade, espiritualidade e crenças pessoais no seu instrumento genérico de avaliação de qualidade de vida", o WHOQOL-100 (World Health Organization Quality of Life Instrument), para avaliar esta dimensão (qualidade de vida e religião) dentro de uma perspectiva transcultural (Fleck et al., 2003).

A religião é uma das práticas mais universais e antigas, praticada por todos os povos. O homem, ao longo da história, sempre manteve uma relação com o sagrado, porém, ao entrarmos na era do conhecimento e do saber mais objetivo, "quando a ciência se impôs como a única capaz de legitimar o campo do conhecimento, a religião foi posta de lado" (Guimarães, 2005, p.175-6).

O período atual caracteriza-se, no entanto, por um momento de transformação (Guimarães, 2005), e volta à cena a legitimidade das crenças religiosas, retornando a importância da religião como promotora do suporte emocional, instrumental e informativo (Faria, Seidl, 2005). Assim, entendemos que o conjunto de crenças relacionadas com aquilo que aquelas mulheres consideravam como sobrenatural, divino, sagrado e transcendental - bem como o conjunto de rituais e códigos morais que derivam dessas crenças - deveria ser entendido, considerado e respeitado.

\section{As mulheres negras, pobres e "de santo"}

Em junho de 2007, a proposta inicial se materializa a partir do cadastramento e atendimento das mulheres vinculadas ao "ilê manjele ô". Nesse dia recebemos os questionários respondidos que haviam sido previamente distribuídos durante uma reunião das mulheres, sendo complementados por outras informações da Ficha Central da SMS RJ.

Sete pessoas se autodeclararam brancas (10,8\%); 34 negras $^{5}(52,3 \%)$ e 24 $(36,9 \%)$ não souberam responder.

Em relação à escolaridade, duas (3,15\%) eram analfabetas; 24 (36,9\%) possuíam Ensino Fundamental incompleto; sete $(10,85)$ tinham Ensino Fundamental completo; três $(4,6 \%)$ com Ensino Médio incompleto; oito $(12,3 \%)$ com Ensino Médio completo, e apenas três $(4,6 \%)$ com nível superior.

Foram realizados oito encontros para atendimento, com intervalos de três a quatro semanas entre eles, no período de junho de 2007 a junho 2008. Foram realizados 182 atendimentos (consultas médicas) para 65 pessoas, de um a 87 anos, assim distribuídos: menores de um ano: zero; de um a quatro anos: dois; de cinco a nove anos: seis; de dez a 14 anos: dois; de 15 a 19 anos: quatro; de vinte a 39 anos: 26; de quarenta a 59 anos: 13; de sessenta a 79 anos: oito; maiores de oitenta anos: três.

\section{As primeiras ações de saúde}

No primeiro dia de ações de saúde com as "mulheres do terreiro", chegamos pela manhã com um enfermeiro, uma auxiliar de enfermagem e um motorista; e caixas com material educativo, formulários padrão da SMS, medicamentos de uso protocolar dos Programas de Hipertensão Arterial e Diabetes, alguns antibióticos, antiparasitários e pomadas de uso ginecológico, além da maca, foco e outros insumos. Montamos, então, o consultório
${ }^{5}$ Negras: pretas, negras, mulatas, pardas. 
simplificado e iniciamos o trabalho de diagnóstico de saúde daquelas mulheres e suas famílias. Na ocasião, realizamos 16 atendimentos médicos, além de desenvolvermos conversas a respeito de planejamento familiar, prevenção de DST-Aids e outras demandadas pelas mulheres.

Retornamos, um mês depois, para dar continuidade ao nosso trabalho, com a mesma equipe, acrescida da cirurgiã-dentista da CAP 3.2 coordenando um grupo de estagiários de Odontologia para as ações de saúde bucal. Nessa ação conjunta, realizamos 15 atendimentos médicos, atividades recreativas e educação em saúde para 13 crianças, além de distribuição de kits de saúde bucal, escovação supervisionada e do exame da cavidade oral de todas. Foram também atendidas vinte mulheres, das quais cinco já saíram encaminhadas e agendadas para o serviço de saúde bucal da Policlínica César Pernetta, para realização de exodontia e outros procedimentos.

Desde então, temos realizado ações de atenção básica (Brasil, 2001b) em encontros mensais. Também podemos encaminhar e realizar exames complementares, ultrassonografia vaginal, e, recentemente, mamografias de alta resolução. Concomitantemente, temos participado de fóruns de discussão sobre implantação de política de saúde da população negra, para divulgar e avaliar, junto aos parceiros, as ações, possibilidades, desafios e dificuldades. Em outubro, um grupo destas mulheres nos procurou solicitando que as mesmas pudessem ser capacitadas para educação em saúde, para que elas pudessem ser multiplicadoras destes conhecimentos em sua comunidade. Os primeiros temas solicitados foram relativos ao planejamento familiar e prevenção de DST/Aids. Desde então, estamos nos reunindo regularmente com este grupo, utilizando a metodologia e os manuais da Estratégia de Saúde da Família para estas ações educativas.

Outro desafio que se destaca consiste em estabelecer mecanismos formais de sustentabilidade, pois o projeto não responde por todas as necessidades da população-alvo e, de certa forma, nos permite "abrir um olhar analisador" sobre equidade e integralidade das ações de saúde da rede de serviços, sendo necessário ampliar as discussões sobre preconceitos, intolerância religiosa, racismo cordial, "invisibilidade" nos serviços.

\section{Considerações finais}

O estudo analisou a experiência de implantação de um "serviço de saúde" vinculado a um terreiro de candomblé. A análise do material empírico representou apenas uma parte da realidade do cotidiano das ações desenvolvidas no local e em outros fóruns de discussão.

Com base nos achados da pesquisa, foi possível levantar as seguintes questões: a implantação do Projeto "Ilê ayié yaya ilera" baseou-se em argumentos técnicos e foi garantida, política e ideologicamente, pelos gestores do projeto, que assumiram posições de garantidores do processo, embora se percebesse que, após certo tempo, a situação não havia avançado no atendimento às necessidades da população negra vinculada ao terreiro.

Quanto à relação estabelecida entre usuários e o grupo de mulheres atendidas, um fator que mereceu ressalva foi o vínculo estabelecido entre o grupo, a líder religiosa e os profissionais de saúde voluntários no projeto, permitindo a continuidade de ações e o processo de construção coletiva da organização dos eventos.

Por outro lado, a organização da rede de saúde ainda desfavorece o acesso a todas as ações e serviços para a população negra e de religião de matriz afro-brasileira, e não é possível mudar a realidade por meio apenas de projetos e leis. Alguns gestores e profissionais não se sentem responsáveis pela desigualdade e pobreza, assim não estão comprometidos/solidários com essas mulheres e suas famílias.

Acreditamos que, embora não tenha sido possível esgotar o assunto, cuja complexidade reconhecemos, este estudo sugere que as diferenças nos estágios de envolvimento dos gestores e profissionais de saúde das unidades com a Política de Saúde da População Negra podem estar relacionadas com as características estruturais, gerenciais e culturais dos profissionais de saúde, gestores e unidades de saúde. É necessário que sejam construídos vínculos e responsabilização entre os serviços de saúde e a população para garantir equidade e integralidade. 


\section{Referências}

BRASIL. Relatório de desenvolvimento humano - Brasil 2005. 2005. Racismo, pobreza e violência. Disponível em: <www.pnud.org.br>. Acesso em: 16 jan. 2007.

Ministério da Saúde. OPAS/DFID. Política Nacional de Saúde da População

Negra: uma questão de equidade. Brasília: Ministério da Saúde, 2001a.

. Ministério da Saúde. Guia Prático do Programa de Saúde da Família. Brasília: Ministério da Saúde, 2001b.

. Ministério da Saúde. A implantação da Unidade de Saúde da Família. Brasília: Ministério da Saúde, Secretaria de Políticas de Saúde, Departamento de Atenção Básica, 2000.

. IBGE. Pesquisa Nacional por Amostra de Domicílios. Brasília: IBGE, 1999.

Disponível em: <www.ibge.gov.br>. Acesso em: 12 jun. 2007.

Ministério da Saúde. Saúde da Família: uma estratégia para a reorientação do $\overline{\text { modelo }}$ assistencial. Brasília, DF: Ministério da Saúde, 1997.

. Ministério da Saúde. Programa de Saúde da Família: saúde dentro de casa. Brasília: Ministério da Saúde, 1994.

BRITO, Ê.J.C.; MALANDRINO, B.C. História e escravidão: cultura e religiosidade negras no Brasil - um levantamento bibliográfico. Rev. Estud. Religião, v.4, n.4, p.112-78, 2007.

CECÍLIO, L.C.O. As necessidades de saúde como conceito estruturante na luta pela integralidade e equidade na atenção em saúde. In: PINHEIRO, R.; MATTOS, R.A. (Orgs.). Os sentidos da integralidade na atenção e no cuidado de saúde. Rio de Janeiro: Cepesc, 2001. p.113-26.

CRUZ, I.C.F. O negro brasileiro e a saúde: ontem, hoje e amanhã. Rev. Esc. Enferm. USP, v.27, n.3, p.317-27, 1993.

DALGALARRONDO, P. Estudos sobre religião e saúde mental realizados no Brasil: histórico e perspectivas atuais. Rev. Psiquiatr. Clin., v.34, supl.1, p.25-33, 2007.

FARIA, J.B.; SEIDL, E.M.F. Religiosidade e enfrentamento em contextos de saúde e doença: revisão de literatura. Psicol. Reflex. Crit., v.18, n.3, p.381-9, 2005.

FERRETI, M. Opressão e resistência na religião afro-brasileira. In: SIMPÓSIO NACIONAL DE HISTÓRIA DAS RELIGIÕES, 3., 2001, Recife. Anais... Recife, 2001. Disponível em: $<$ www.orixas.com.br/portal/index.php?option =com_content\&task=view\&id=33\&ltemid $=1-28 \mathrm{k}->$. Acesso em: 23 jun. 2007.

FLECK, M.P.A. O instrumento de avaliação de qualidade de vida da Organização Mundial da Saúde (WHOQOL-100): características e perspectivas. Cienc. Saude Colet., v.5, n.1, p.33-8, 2000.

FLECK, M.P.A. et al. Desenvolvimento do WHOQOL, módulo espiritualidade, religiosidade e crenças pessoais. Rev. Saude Publica, v.37, n.4, p.446-55, 2003.

GOMES, M.C.P.A. Acolhimento, vínculo e integralidade: o poder do discurso ou o discurso sem poder? Um estudo sobre as práticas cotidianas de Saúde da Família em grandes centros Urbanos. 2005. Dissertação (Mestrado) - Instituto de Medicina Social, Universidade do Estado do Rio de Janeiro, Rio de Janeiro. 2005.

GUIMARÃES, M.B.L. Feminização da pobreza e religiosidade. In: VALLA,V.V.; STOTZ, E.N.; ALGEBAILE, E.B. (Orgs.). Para compreender a pobreza no Brasil. Rio de Janeiro: Contraponto, 2005.

HERINGER, R. Desigualdades raciais no Brasil: síntese de indicadores e desafios no campo das políticas públicas. Cad. Saude Publica, v.18, supl., p.57-65, 2002. 
JENSEN, T.G. Discursos sobre as religiões afro-brasileiras: da desafricanização para a reafricanização. Rev. Estud. Relig., v.1, n.1, p.1-21, 2001.

LEAL, M.C.; GAMA, S.G.N.; CUNHA, C.B. Desigualdades raciais, sociodemográficas e na assistência ao pré-natal e ao parto, 1999-2001. Rev. Saude Publica, v.39, n.1, p.100-7, 2005.

MACHADO, K.; CARVALHO, M. Invisibilidade: a maior das dores. Saúde da população negra. RADIS, n.20, p.8-11, 2004.

MAGALHÃES, R. Integração, exclusão e solidariedade no debate contemporâneo sobre as políticas sociais. Cad. Saude Publica, v.17, n.3, p.567-79, 2001.

MATTOS, R.A. Os sentidos da integralidade: algumas reflexões acerca de valores que merecem ser defendidos. In: PINHEIRO, R.; MATTOS, R.A. (Orgs.). Os sentidos da integralidade na atenção e no cuidado de saúde. Rio de Janeiro: Cepesc, 2001. p.39-64.

MINAYO, M.C.S.; ASSIS, S.G.; SOUZA, E.R. (Orgs.). Avaliação por triangulação de métodos: abordagem de programas sociais. Rio de Janeiro: Fiocruz, 2005.

NASCIMENTO, M.N.F. Religiosidade e saúde. Disponível em: <www.psicologia.com. pt>. Acesso em: 21 abr. 2008.

OLIVEIRA, F. Ser negro no Brasil: alcances e limites. Est. Avançados, v.18, n.50, p.57-60, 2004.

PAIXÃO, M. Desigualdades raciais no estado do Rio de Janeiro: um panorama através dos indicadores do Censo 2000. (nota de Estudo 05/2003, mimeogr.).

PINHEIRO, R.; MATTOS, R.A. Os sentidos da integralidade na atenção e no cuidado de saúde. Rio de Janeiro: Cepesc, 2001.

PÔRTO, A. O sistema de saúde do escravo no Brasil do século XIX: doenças, instituições e práticas terapêuticas. Hist. Cienc. Saude - Manguinhos, v.13, n.4, p.1019-27, 2006.

REIS, E. Percepções da elite sobre pobreza e desigualdade. In: HENRIQUES, R. (Org.). Desigualdade e pobreza no Brasil. Rio de Janeiro: IPEA, 2000. p.487-500.

SILVA, J.M. Religiões e saúde: a experiência da Rede Nacional de Religiões Afro-brasileiras e Saúde. Saude Soc., v.16, n.2, p.171-7, 2007.

SILVA, J.M.; DACACH, S.; LOPES, F. Atagbá: guia para a promoção da saúde nos terreiros. Rio de Janeiro: Rede Nacional de Religiões Afro-brasileiras e Saúde, 2005.

SILVA, V.G. Prefácio ou notícias de uma guerra nada particular: os ataques dos neopentecostais às religiões afro-brasileiras e aos símbolos da herança africana no Brasil. In:_. (Org.). Intolerância religiosa: impactos do neopentecostalismo no campo religioso afro-brasileiro. São Paulo: Edusp, 2007. p.9-28.

SPINK, M.J.; MENEGON, V.M. A pesquisa como prática discursiva: superando os horrores metodológicos In: SPINK, M.J. (Org.). Práticas discursivas e produção de sentidos no cotidiano: aproximações teóricas e metodológicas. 2.ed. São Paulo: Cortez, 2000. p.6392.

TORRES, H.G.; MARQUES, E. Políticas sociais e território: uma abordagem metropolitana. São Paulo Perspec., v.18, n.4, p.3-7, 2004.

TRAMONTE, C. Com a bandeira de Oxalá: trajetória, práticas e concepções das religiões afro-brasileiras da grande Florianópolis. Itajaí: Univali Lunardelli, 2001.

TRAVASSOS, C.; MARTINS, M. Uma revisão sobre conceitos de acesso e utilização de serviços de saúde. Cad. Saude Publica, v.20, supl.2, p.5, 2004. 
A Política Nacional de Saúde Integral da População Negra definiu o conjunto de princípios, diretrizes e objetivos voltados para a melhoria das condições de saúde dessa população, incluindo, entre outras, ações de cuidado e atenção à saúde, visando à promoção da equidade e integralidade em saúde. Este trabalho relata a experiência de implantar um serviço de saúde vinculado a um terreiro de candomblé. Na condução do projeto encontramos apoio de gestores e profissionais, mas surgiram alguns obstáculos (preconceitos, intolerância religiosa, racismo cordial, "invisibilidade"). Iniciamos o diagnóstico de saúde das mulheres e suas famílias e desenvolvemos ações de atenção e de educação em saúde. O desafio que se destaca consiste em estabelecer mecanismos de sustentabilidade, pois o projeto não responde por todas as necessidades do grupo e nos permitiu "abrir um olhar analisador" sobre equidade e integralidade das ações de saúde para a população negra vinculada a religiões de matriz afro-brasileira.

Palavras-chave: Grupo com ancestrais do continente africano. Integralidade. Religião de matriz afro-brasileira. Equidade em saúde.

Ylê ayié yaya ilera (full health in the house of this existence): equity and comprehensiveness in healthcare for the Afro-Brazilian religious community

The National Comprehensive Healthcare Policy for the black population has defined a set of principles, guidelines and objectives for improving this population's health conditions, including healthcare and attendance actions, among others, with the aim of promoting healthcare equity and comprehensiveness. This paper describes the experience of implementing a healthcare service linked to a Candomble yard. In undertaking the project, we found support from managers and professionals, but there were some obstacles (prejudice, religious intolerance, cordial racism and "invisibility"). We began to diagnose women's health and their families' health, and we developed healthcare and health education actions. The challenge that stood out was to establish mechanisms for sustainability, since the project did not meet all the needs of the group, while it allowed us to "open an analytical eye" regarding equity and comprehensiveness of healthcare actions for the black population with links to Afro-Brazilian religions.

Keywords: African continental ancestry group. Integral health care. Afro-Brazilian religion. Equity in health.

\section{Yle ayié yaya ilera (Salud plena en la casa de esta existencia): equidad e integralidad en salud para las comunidades religiosas afro-brasileñas}

La Política Nacional de Salud Integral de la Población Negra ha definido el conjunto de principios, directrices y objetivos relacionados a la mejora de las condiciones de salud de esta población incluyendo, entre otras, acciones de cuidado y atención a la salud visando la promoción de la equidad e inegralidad en salud. Este trabajo relata la experiencia de implantar un servicio de salud vinculado a un "terreiro de candomblé". En la realización del proyecto encontramos apoyo de gestores y profesionales pero surgieron algunos obstáculos (preconceptos, intolerancia religiosa, racismo codial, "invisibildad"). Iniciamos el diagnóstico de salud de las mujeres y de sus familias y desarrollamos acciones de atención y educación en salud. El desafío principal consiste en establecer mecanismos de sustentabilidad pues el proyecto no responde por todas las necesidades del grupo y nos permitió "abrir una mirada analizadora" sobre la equidad y la integralidad de las acciones de salud para la población negra vinculada a religiones de matriz afro-brasileña.

Palabras clave: Grupo de ascendência continental africana. Integralidad. Religión de matriz afro-brasileña. Equidad em salud. 